\title{
Missing in action - the meaning of cell death in tissue damage and inflammation
}

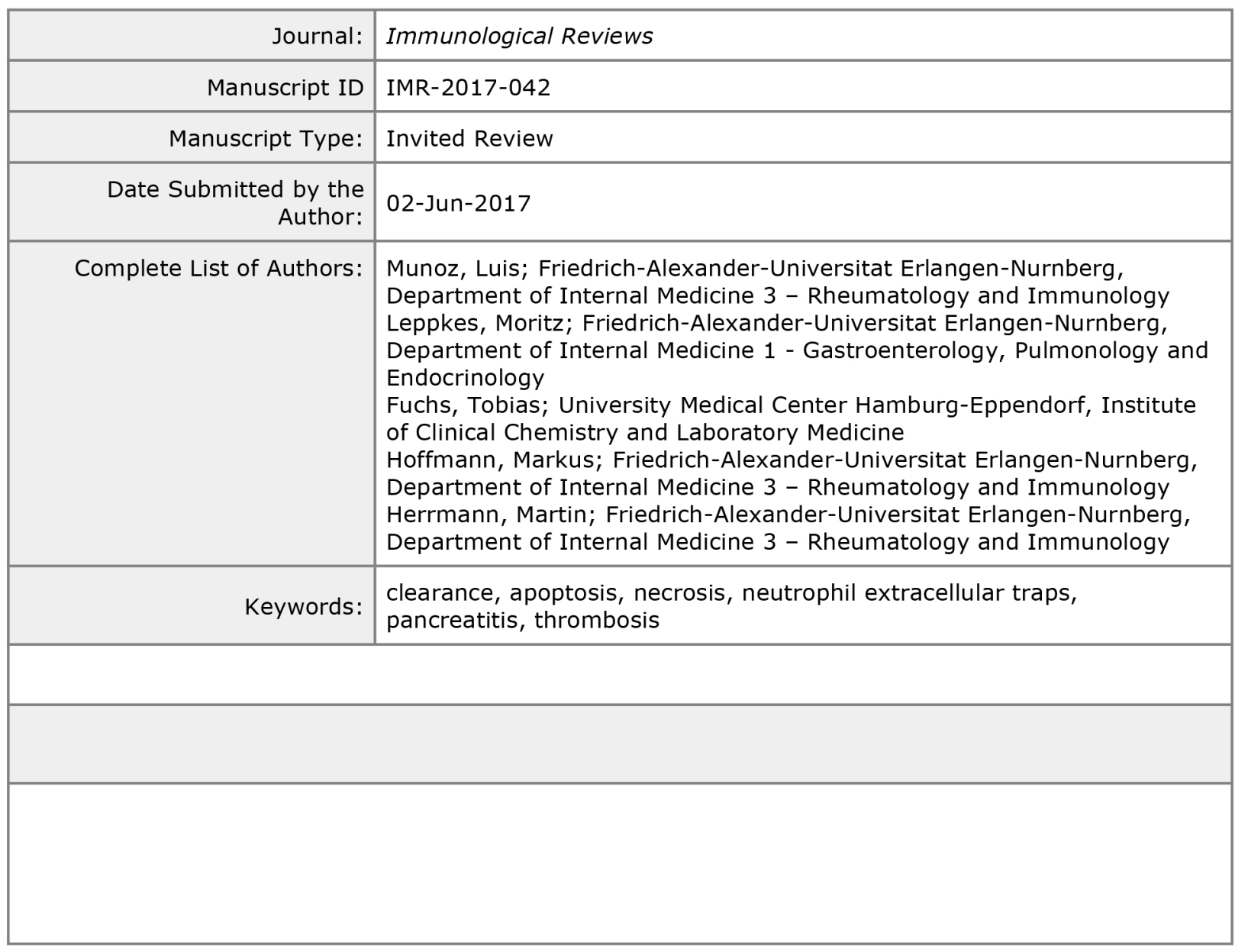




\section{Missing in action - the meaning of cell death in tissue damage and inflammation}

Luis E. Muñoz ${ }^{1 *}$, Moritz Leppkes ${ }^{2}$, Tobias A. Fuchs ${ }^{3}$, Markus Hoffmann ${ }^{1}$ and Martin Herrmann ${ }^{1 *}$

${ }^{1}$ Friedrich-Alexander-University Erlangen-Nürnberg (FAU), Department of Internal Medicine 3 - Rheumatology and Immunology, Universitätsklinikum Erlangen, Erlangen, Germany.

${ }^{2}$ Friedrich-Alexander-University Erlangen-Nürnberg (FAU), Department of Internal Medicine 1 - Gastroenterology, Pulmonology and Endocrinology, Universitätsklinikum Erlangen, Friedrich-Alexander-University Erlangen-Nürnberg (FAU), Erlangen, Germany.

${ }^{3}$ University Medical Center Hamburg-Eppendorf, Institute of Clinical Chemistry and Laboratory Medicine, Hamburg, Germany.

All authors equally contributed

${ }^{*}$ Address correspondence to:

Martin Herrmann (Martin.Herrmann@uk-erlangen.de) or Luis E. Muñoz (Luis.Munoz@ukerlangen.de), Friedrich-Alexander-University Erlangen-Nürnberg (FAU), Department of Internal Medicine 3 - Rheumatology and Immunology, Universitätsklinikum Erlangen, Ulmenweg 18, 91054 Erlangen, Germany.

Phone: +49 91318536990 ;

Fax: +4991318535776 . 


\section{Running title}

Cell death in homeostasis, inflammation and repair

\section{Summary}

Billions of cells die every day in higher organisms as part of the normal process of tissue homeostasis. During special conditions like in development, acute infections, mechanical injuries, and immunity, cell death is a common denominator and it exerts profound effects in the outcome of these scenarios. In order to prevent the accumulation of aged, superfluous, infected, damaged and dead cells, professional phagocytes act in a rapid and efficient manner to clear the battle field and avoid spread of the destruction. Neutrophils are the most abundant effector immune cells that extravasate into tissues and can turn injured tissues into gory battle fields. In peace times neutrophils tend to patrol tissues without provoking inflammatory reactions. We discuss in this review actual and forgotten knowledge about the meaning of cell death during homeostatic processes and drive the attention to the importance of the action of neutrophils during patrolling and for the maintenance or recovery of the homeostatic state once the organism gets attacked or injured, respectively. In this fashion we disclose several disease conditions that arise as collateral damage of physiological responses to death.

\section{Keywords}

Clearance, apoptosis, necrosis, neutrophil extracellular traps, pancreatitis, thrombosis 


\section{Clearance of apoptotic and necrotic cells}

\section{The quiet banquet}

The impairment of the clearance of apoptotic cells has been suggested to be responsible for the initiation of systemic autoimmunity in several chronic inflammatory conditions, including the prototypic disease systemic lupus erythematosus (SLE) $(1,2)$. Apoptosis was initially recognized as a form of programmed cell death occurring during development and considered important to maintain tissue homeostasis (3). Apoptotic cells are engulfed at very early states by phagocytes in an immunologically silent process (4). The silent clearance is warranted since apoptotic cells expose the phospholipid phosphatidylserine (5) while maintaining their plasma membrane integrity, thus preventing release of cellular constituents into the surrounding interstitial tissue (6). Thus the recognition of aged, apoptotic and damaged cells is granted by redundant mechanisms that start with the attraction of phagocytes to the site of demise.

\section{The way to the prey}

A plethora of mediators compose a complex and often redundant system including ATP, UTP (7), sphingosine-1-phosphate (8), lysophosphatidylcholine (9) and fractalkine (CX3CL1) (10). The release of such "find me" signals by dying cells stimulates migration and activation of leukocytes (11). The migration of neutrophils toward dying cells is inhibited by secretion of lactoferrin, which acts like a "keep out" signal (12). In case of an enhanced collateral activation of neutrophils, lactoferrin would also contribute to dampening of inflammation by enhancing the aggregation of NETs (neutrophil extracellular traps) (13) (14).

\section{The cutlery for "la grande bouffe"}

The distinction between viable and dying cells is mediated by subtle changes in the plasma membrane including the glycocalix (15) and phospholipids. Phosphatidylserine is a phospholipid present in the inner leaflet of the plasma membrane and gets translocated to the outer leaflet during early stages of apoptosis. Moreover, the increase of the lateral mobility and density of phosphatidylserine on dying cells represents a pivotal event for the recognition as "eat me" signal by phagocytes $(16,17)$. The receptors on phagocytes directly involved in the recognition of phosphatidylserine are Tim-1, Tim-4, Bai-1 and Stabilin-2 (18). Phosphatidylserine can also be recognized indirectly by phagocytes through several 
bridging molecules such as the Milk fat globule EGF factor 8 (MFG-E8) (19), the C-reactive protein (CRP) or growth arrest-specific 6 (Gas-6) $(20,21)$. The engulfment takes place after the rearrangement of the cytoskeleton to form a phagosome which transfers dead cell cargo to lysosomes in a process referred to as phagosome maturation (7). The molecular pathways involved in the engulfment of apoptotic cells are still a matter of intense research (22).

\section{Siesta - calming down and digest}

The consequence of the uptake by phagocytes of apoptotic cells is the secretion of "tolerate me" mediators such as transforming growth factor $\beta$ (TGF- $\beta$ ) and interleukin-10 (IL-10), which further inhibits the enrollment of inflammatory cells at the site of cell demise. The uptake by alternatively activated resident macrophages of apoptotic cells additionally orchestrates the clearance process by generating 12/15-lipoxigenase-derived products essential for the anti-inflammatory outcome (23). The secretion of pro-inflammatory cytokines like TNF- $\alpha, \mathrm{IL}-1 \beta$, and IL-12 is also actively downregulated by the phagocytosis of apoptotic cells (4). After engulfment of apoptotic thymocytes, tissue-resident macrophages respond with the inhibition of NF-KB signaling and repression of inflammatory cytokines, such as IL-12. In the pristane-induced murine lupus this downregulation is mediated by the nuclear receptor Nr4a1 (24). The bottom line is that the clearance of apoptotic cells actively creates an anti-inflammatory milieu wherever cells undergo homeostatic apoptosis (25) (Fig. 1).

\section{Fake food}

The intrinsic immunosuppressive effect of phosphatidylserine exposure has been hijacked by numerous viruses, microorganisms, and parasites to support establishment and latency of infection. Indeed, several of the most pathogenic viruses, bacteria and parasites reportedly either expose phosphatidylserine or induce phosphatidylserine exposure in bystander host cells (reviewed in (26)). In the infection with Leishmania major the development of the clinical disease depends on the presence of phosphatidylserineexposing dead promastigotes in the virulent inoculum (27) (Fig. 1).

In the vicinity of tumors phosphatidylserine is often severely dysregulated and is prone to dampen tumor immunity. Deeper studies of the biology of the apoptotic process allowed the characterization and identification of further recognition domains and ligands like 
incompletely processed carbohydrates, galectins, and several lectins (28-30). In these studies it was ascertained that the progression of cell death has broad effects on the outcome of the immune response. The use of AxA5 knockout mice suggested that masking by annexin A5 (AxA5) of phosphatidylserine increases the immune response against tumor cells. Endogenous AxA5 thus acts as a proinflammatory protein to render dying tumor cells immunogenic upon injection $(31,32)$. The inhibition of phosphatidylserine recognition by exogenously added AxA5 heightened the immunogenicity of irradiated cells $(33,34)$ (Fig. 1).

The orchestration of the immunologic tolerance, rejection and the host responses to dying cells are modulated by specific forms of cell death developing in the living organism (35). Employing an established doxycycline-regulated inducible system that allows triggering various types of cell death directly in vivo, the modulatory potential of dead and dying cells was directly evaluated in models of allogeneic tumor/graft rejection (36) and for syngeneic tumors implanted into previously immunized mice (37). In these studies we demonstrated that timing of the release of damage associated molecular pattern (DAMP) crucially determines the outcome of the immune response. All these findings have potential implications in the field of tumor immunology as well as in chronic auto-inflammation (21).

\section{Stodgy food and lousy eaters}

When apoptotic cells are not cleared in time, they progress to secondary necrosis losing their membrane integrity and releasing modified autoantigens of nuclear origin together with DAMPs. During apoptosis, a substantial amount of nuclear high mobility group box 1 protein (HMGB1) gets tightly attached to hypoacetylated chromatin, preventing its release (38). In secondary necrosis, HMGB1 is released tightly bound to nucleosomes which in turn contribute to the break of immunological tolerance against DNA (39), the key autoantigen of SLE.

The first hint on a phagocytic defect (for yeast) in patients with SLE was reported back in 1980 (40). In vitro differentiated monocyte-derived macrophages from SLE patients showed a decreased and delayed engulfment of autologous apoptotic material $(1,2)$. They display reduced adherence (41) and a lower expression of the cell adhesion receptor CD44 (42). Adherence and phagocytosis are closely related processes that reflect the clearance capacity of phagocytes. However, an effect of the therapy could not be excluded in these 
studies. In order to overcome this, CD34 positive hematopoietic stem cells were isolated from peripheral blood of SLE patients and showed reduced differentiation abilities to professional macrophages (43) suggesting an intrinsic phagocytic defect in a subgroup of patients with SLE.

The autoimmune responses in patients with SLE display attributes of an antigen-driven T cell-dependent immune response, which actually takes place in the germinal centers of secondary lymphoid organs $(44,45)$. The investigation of the clearance process in the germinal centers of non-autoimmune patients shows tingible body macrophages containing engulfed TUNEL-positive material but seldom free apoptotic nuclei. In some patients with SLE, the amount of tingible body macrophages found in germinal centers was reduced and the TUNEL-positive material was to be found associated with follicular dendritic cells (46). These cells have the ability to expose the dead cell-derived autoantigens to autoreactive $B$ cells that have been accidentally generated by somatic hypermutation. This challenges one checkpoint for the development of tolerance and finally fosters the formation of long-lived auto-reactive plasma cells and consequently the initiation of autoimmunity (47). AntidsDNA, anti-histone, anti-Sm, anti-SS-B/La, anti-ribosomal (Ro), and anti-ribonucleoprotein (U1RNP) are produced in patients with SLE and constitute the group of anti-nuclear autoantibodies (ANA) (48). Similarly, anti-phospholipid (49) and anti-C1q autoantibodies are associated with some manifestations of SLE like anti-phospholipid syndrome and lupus nephritis, respectively (50). The existence of ANAs is considered important evidence that a clearance deficiency is directly involved in the initiation of the autoimmune phenomena in SLE (25).

\section{When mice are tablemates}

Further evidence can be obtained from several murine models that target clearanceassociated proteins and are accompanied by autoantibody production. Knock-out mice for the tyrosine kinase c-Mer (51) and MFG-E8 (19) which recognize apoptotic cells through Gas6 and integrin receptors display a defective phagocytosis of apoptotic cells and develop autoantibodies against DNA and chromatin over time $(52,53)$. Extracellular chromatin is cleared very efficiently by the action of endonucleases like DNase 1. Loss of function or reduced expression of the DNase 1 gene has been found in affected kidneys of lupus prone NZBXNZW mice (54). The action of the intracellular DNase II expressed in bone marrow macrophages is extremely important for the prevention of lethal autotoxicity mediated by 
type I IFNs (55). When DNase II is deleted and the consequent type I IFN response is avoided by the additional deletion of the IFN type I receptor, the mice develop ANAs and chronic polyarthritis. In this setting the digestion of engulfed nuclei from erythroid precursors is impaired (56) and this might also contribute to the initiation of the autoimmune response by the accumulation of nuclear debris. Natural IgM, along with C1q, facilitates engulfment of dead cells by macrophages in the steady state. Quartier et al. showed phagocytic activity of macrophages is reduced 3 to 4 fold in the absence of $\operatorname{lgM}(57)$. The role of natural $\operatorname{lgM}$ together with further complement proteins during the clearance of apoptotic cells is under debate. It has been postulated that natural IgM antibodies facilitate and promote the silent clearance of apoptotic cells by binding autoantigens with higher avidity than autoreactive IgG antibodies (21). Under the inflammatory conditions after the injection of the alkane oil pristane in mice, IgM seems to contribute to the establishment of the IFN signature (58).

\section{When humans meet at the round table}

Genetic defects in the early components of the classical complement pathway are associated with a high risk (>80\%) of developing SLE (59). C1q is a strong opsonin for phagocytosis of late apoptotic and necrotic cells and is essential for an effective uptake of degraded chromatin by monocyte-derived phagocytes (60). The rare deficiencies of the complement proteins $\mathrm{C} 2$ and $\mathrm{C} 4$ are also associated with SLE, glomerulonephritis, and infections $(61,62)$. Complement receptors and complement inhibitors have also been strongly associated with the development of the IFN signature in $\operatorname{SLE}(63,64)$. Further opsonins like CRP, SAP and the long Pentraxin 3 (PTX3) bind apoptotic material and initiate back-up mechanisms for the clearance of apoptotic cells. In humans, CRP is the main acute phase protein and binds to damaged cell membranes and nuclear components, like U1 snRNP and histones $(65,66)$. SAP binding to exposed histones contributes to the solubilization of chromatin for further degradation. PTX3 binds to late apoptotic cells and its deficiency leads to a disturbed clearance of apoptotic cells. All these serum proteins are recognized by antibodies from patients with SLE (67-70) meaning that they are present at the crime scene when the breakdown of tolerance has happened.

\section{Spoiled food temptation}

The evidence supporting the notion that an impaired clearance of apoptotic cells is involved in the initiation of the autoimmune response has been presented above. The plethora of 
factors involved in the etiopathology SLE reflects the complexity of the disease and confirms its multifactorial and multigenetic origin. Considering the chronic nature of the disease one has to assume that the factors conditioning the impaired clearance persist throughout the whole lifespan of the affected individual. This means that remnants of noncleared apoptotic cells accumulate in tissues of patients with SLE every single day. However, most reports of non-engulfed cellular debris in human tissues besides the lymph nodes (46) date before 1960 and lack modern technology. In the 1950s when the patients were only treated with cortisone, studies reported hematoxylin bodies in cardiac lesions of patients with SLE (71). They were defined as exclusively extracellular, single, clustered, or coalescent masses found specifically in $70-90 \%$ of the tissues of mostly untreated patients with SLE (72). They originated from a characteristic alteration of nuclei of mesenchymal cells $(73,74)$. Regrettably, no association between the presence of this alterations and cell death was made at that time, since the process of apoptosis was first described much later (3). Intensive search for hematoxylin bodies in other diseases were unsuccessful and thus they were considered a reliable criterion for the diagnosis of SLE in necropsies $(73,74)$. An overview of the studies which systematically looked for hematoxylin bodies is presented in table 1. Obtaining similar evidence nowadays is probably impossible since these observations were made in virtually untreated patients and the cause of death was SLE. This warrants that the picture obtained from those necropsies reflected the real situation of the untreated disease, with less than 50\% 5-year survival in 1955 (75).

\section{The hangover}

Tissue-borne Secondary NEcrotic Cells (SNEC) are not only involved in the etiology but also the pathogenesis of SLE. SNEC include proteins that were subjected to caspase cleavage and further post-translational modifications such as phosphorylation, dephosphorylation, ubiquitination, acetylation, and citrullination. SNEC comprise neoepitopes that challenge the immunological tolerance and foster auto-immunogenicity (76). When anti-nuclear antibodies appear, the formation of immune complexes and the consequent activation of the complement system are programmed.

The inflammation caused by immune complexes is additionally fueled by the involvement of neutrophils, monocytes, and inflammatory macrophages in the clearance process. Sera from patients with SLE often enhance the phagocytosis by macrophages of apoptotic (77) and necrotic cells (78). Anionic phospholipids, particularly phosphatidylserine, are generally 
concentrated at the surfaces of apoptotic cells. $\beta 2$-glycoprotein-1 and AxA5 bind phosphatidylserine and decorate apoptotic cells. IgG from SLE patients with antiphospholipid syndrome also binds to these proteins on non-cleared late apoptotic cells, enhancing their inflammatory potential by the concurrent secretion of TNF- $\alpha$ (49). Activating complement and engaging Fc receptors, sensibilization of SNEC, either with ANA or with anti-opsonin antibodies, shifts their usually silent clearance towards inflammation (79) (Fig. 1). Supplementation of healthy blood with IgG from patients with SLE enhances ingestion of SNEC by neutrophils and monocytes $(70,80)$. The uptake of IgG-sensitized SNEC is tightly coupled with the secretion of various pro-inflammatory cytokines like IL-8, IL-1 $\beta$, TNF- $\beta$, IL18 and IFN- $\alpha(67,80)$.

Several additional players have been identified determining the pathogenicity of autoreactive IgG from patients with SLE and the consequences of its binding to autoantigens. The disease activity of SLE patients positively correlated with the exposure of fucosyl residues on immobilized IgG complexes (81). The non-pathogenic anti- $\beta 2-$ glycoprotein-1 antibodies of the IgG isotype derived from healthy children display an increased sialylation when compared to pathogenic ones from adults with anti-phospholipid syndrome (82). Pathogenic anti-histone-lgG was mainly present in the non-sialylated fraction and only non-sialylated anti-SNEC IgG promoted SNEC-uptake by neutrophils. The sialylation of specific anti-histone-lgG directly shifted the inflammatory response to SNEC towards a milder form (83). The control of the inflammatory potential of autoantibodies in a model of autoimmune arthritis was governed by the TH17-IL-23 axis. This particular T helper subset regulated the expression of $\beta$-galactoside $\alpha 2,6$-sialyltransferase 1 in antibodyproducing $B$ cells and modulated the glycosylation profiles and activity of IgG produced by newly formed plasma cells (84). Immune complexes containing nucleic acids are shuttled by autoantibodies into the intracellular milieu of innate immune cells, triggering inflammatory cytokine responses $(80,85)$. The overload of phagocytes with nucleic acids has been shown to trigger the exaggerated type I IFN response in DNase2 knockout mice (56). Therefore, we consider nucleic acid containing immune complexes a SLE-specific binary pathogen that precipitates the clinical manifestations of the disease. 


\section{Dealing with danger, death and collateral damage - How neutrophil cell death regulates inflammation}

\section{Catch and kill: the cellular retiarius at work}

The neutrophil granulocyte is known as the prototype gladiator amongst cells. Besides of the classical neutrophil armory phagocytosis (and subsequent destruction of the opponent in phagolysosomes) and degranulation, neutrophils possess an additional mechanism in their arsenal: the formation of neutrophil extracellular traps (NETs). Described initially as a defense mechanism against bacteria and a highly organized and reactive oxygen species (ROS)-dependent active process $(86,87)$, during the last decade many studies identified numerous triggers (88) and pathways of NET formation (89) and discussed their contents, morphology (90), and the consequences for the NETting cell (91). In this almost Babylonian confusion among published data, the lowest common denominator is that the formation of a NET results in the extrusion of a meshwork of DNA decorated with granular contents into the surrounding extracellular milieu. Thus, NETosis is a particularly dirty kind of cell death with a supposedly inflammatory outcome.

\section{The Janus-faced gladiator: neutrophils in inflammation and autoimmunity}

Accordingly, when it comes to autoimmune or autoinflammatory diseases neutrophils were mostly allotted the role of a villain that fuels aberrant immune responses and causes tissue damage. In the development of SLE, the prototypical systemic autoimmune disease, many aspects of neutrophil biology and especially NETs have been implicated (92). NETs are a potential source of SLE autoantigens and are therefore prime candidates for the initiation or enhancement of autoimmunity and tissue damage (Fig. 2). SLE patients produce autoantibodies against many antigens associated with NETs $(93,94)$. In patients with defective NET degradation levels of anti-NET and anti-dsDNA autoantibodies are further increased and accompanied by renal damage (95). Neutrophils and their NETs have also been connected with development of anti-citrullinated protein antibodies (ACPA) and RA (96), with gout and many other inflammatory disorders (97). Supporting evidence for a proinflammatory role of NETs comes from encouraging results of studies using PAD4-inhibitors in lupus and other autoinflammatory conditions (98-101). However, some important findings do not go along with an exclusively pro-inflammatory role of neutrophils and NETs: firstly, human individuals that are unable to form NETs do not fit in this line of arguments. The 
outcome of a deficiency of NET-formation in humans can be observed in individuals with chronic granulomatous disease (CGD) and Papillon-Lefèvre syndrome (PLS). In CGD, ROS-dependent NET-formation is impaired due to mutations in the NADPH oxidase complex 2 (102). Individuals with CGD do not only suffer from recurring bacterial and fungal infections, but are also prone to develop autoimmune syndromes (103), which cannot be explained by the inability to clear pathogens. In PLS, NET-formation is compromised by a mutated Cathepsin $C$ that renders all neutrophil serine proteases inactive and therefore impedes chromatin decondensation and canonical NET formation $(104,105)$. Subjects with PLS are characterized by hyperactivation of neutrophils resulting in exaggerated and nonresolving inflammation, especially in the oral cavity and the skin (106). Interestingly, in experimental lupus and gouty arthritis neutrophil depletion or neutropenia worsens disease $((14,107))$. Also mice strains with normal neutrophil numbers but defects in NET formation have exacerbated and unresolving inflammation. So aside from their given role as the arsonist, neutrophils in general and NETs in particular apparently can have outright antiinflammatory functions as well.

\section{Yin and Yang: the role of NETs in lupus}

In 2012, the group of Mark Shlomchik reported that Nox2-deficient lupus-prone MRL.Fas ${ }^{\text {Ipr }}$ mice developed aggravated lupus, including elevated autoantibody titers and worsened glomerulonephritis (108). These results were recently substantiated and extended by our own studies showing that a mouse strain that carries a mutation in one of the subunits of Nox2 that abrogates Nox2-dependent ROS-production (Ncf1** mice) exhibited spontaneous production of hallmark lupus autoantibodies and subclinical inflammation in the kidneys (109). A widely used experimental lupus model develops after intraperitoneal injection of 2,6,10,14-tetramethylpentadecane (pristane), an alkane oil that induces various forms of cell death, among them ROS-dependent formation of NETs $(110,111)$. Pristane-induced lupus (PIL) was drastically worsened in Ncf1 ${ }^{\star \star}$ mice (107). Pristane-injected Ncf1 ${ }^{\star \star}$ mice had higher levels of $\lg G 1$ and $\lg$ G2a lupus autoantibodies accompanied by increased deposition of IgG and complement $\mathrm{C} 3$ in the kidneys that resulted in early proteinuria and premature death. In addition, Ncf1 ${ }^{\star \star}$ mice also developed strongly exacerbated arthritis after pristane-injection. The absence of ROS impacts cells on many levels and therefore likely has further global influences on lupus than the inability of NET formation (112). We therefore also investigated PIL in mice deficient in peptidyl arginine deiminase 4 (PAD4), 
crucial for NET formation in response to calcium-dependent triggers (113). Similar to Ncf1** mice, PAD4-deficient mice exhibited higher autoantibody levels and enhanced proteinuria (107). In a parallel study by the Shlomchik lab (114), PAD4-deficiency or pharmacological inhibition of PAD4 did not have any effect on tolerance loss, immune activation, or nephritis in the MRL.Fas ${ }^{\text {Ipr }}$ lupus model.

Interestingly, in our study strongly diminished levels of NETs were found in the pristaneinjected peritoneum of both Ncf1 ${ }^{\star \star}$ and PAD4 knockout mice, showing that pristane-induced NET-formation is augmented by the oxidative burst and citrullination of histones by PAD4. In contrast, we detected a higher percentage of NETs in the blood of Ncf1** mice, even before injection of pristane. This was also apparent in patients with SLE and might reflect a pre-primed status of neutrophils derived from Ncf1** mice and SLE patients due to subclinical or overt inflammation. Whereas increased presence of NETs in the blood in lupus might fuel the inflammatory process, NET formation in the enclosed pristane-injected peritoneal cavity therefore appears to be an important factor dampening inflammation. The multifaceted role of NETs on autoimmunity and inflammation warrants caution regarding the development of PAD4 inhibitors for the treatment of lupus and inflammatory diseases.

\section{The neutrophil: the acute gout attack's arsonist and firefighter}

Also in a mouse model of gouty arthritis reduction of NET formation in Ncf1** mice resulted in chronification of the disease $(14,115)$. Gout is the prototype of an acute self-limiting inflammation in the joints. It results from precipitation and tissue deposition of uric acid in the form of monosodium urate (MSU) crystals, which trigger an inflammatory response accompanied by severe pain, swelling, and erythema. The immense inflammatory potential of acute gout is explained by induction of inflammatory cytokine release by MSU crystals from monocytes and neutrophils. Ingestion of MSU crystals by macrophages results in the intracellular liberation of large amounts of sodium cations that cause osmotic imbalance, drop of intracellular potassium, activation of the NALP3 inflammasome and finally the secretion of the inflammatory cytokines IL-1 $\beta$ and IL-18 and recruitment of neutrophils (116). Also neutrophils ingest MSU crystals, form NETs (117), and release a variety of inflammatory mediators (e.g., TNF- $\alpha$ and IL-6), neutrophil chemoattractants and activators (e.g., IL-8, MIP-1 $\alpha$ and IP-10) that initially intensify inflammation $(118,119)$. Remarkably, gouty attacks usually fade within 3-10 days, though MSU crystals are still present in the tissue. Interestingly, antibody-mediated depletion of neutrophils delayed arthritis onset but 
also abrogated its spontaneous resolution (14). A similar phenotype was observed in a neutropenic mouse strain (115). Thus, in gouty arthritis neutrophils appear to function as both arsonists and firefighters.

\section{How neutrophils dampen the fire of inflammation}

Although neutrophils are usually regarded as pro-inflammatory cells mediating inflammation, evidence is increasing that they can also have anti-inflammatory and immunosuppressive functions. In cancer, immunosuppressive neutrophils are often referred to as granulocytic myeloid-derived suppressor cells (g-MDSC). G-MDSC exist as mature and immature (banded) cells, are able to form NETs (120), and are often of lower densities, co-purifying with PBMCs in density gradient centrifugation, although their granularity is not different from high density neutrophils (121). Of note, low density neutrophils (LDN) with a similar phenotype exert pro-inflammatory functions in the blood of lupus patients due to their high rates of spontaneous NET-formation (122). In cancer however such cells have been shown to suppress $T$ cell responses by releasing arginase-1, a ureohydrolase degrading arginine, which is essential for T cell activation and proliferation (123).

Additional, though indirect evidence that neutrophils often have a regulatory role in inflammation comes from multipotent mesenchymal stromal cells (MSC), a cell type with immunoregulatory and regenerative function. Rather than suppressing neutrophil function, MSCs promote the survival of neutrophils and increase the capacity of the respiratory burst and their activities (124).

Another way of action how neutrophils dampen inflammation is by action of their proteases. Neutrophils contain several protease classes, including cysteine proteases (e.g. cathepsin C, also termed dipeptidyl peptidase I), metalloproteases (e.g. collagenases and gelatinases), and serine proteases. Neutrophil serine proteases (NSP) consist of neutrophil elastase (NE), proteinase 3 (PR3), cathepsin G, and neutrophil serine protease 4 (118). NE, PR3, and cathepsin G are among the most-abundant neutrophil proteins with approximately 1-3 pg per cell. NSPs target a broad array of proteins for modification and degradation. They degrade the extracellular matrix components elastin, laminin, type IV collagen, vitronectin, and fibronectin and enable their migration through the tissue. They also process cytokines and chemokines and their receptors and thus modulate their bioactivity and availability (14). For instance, cleavage by NSPs of TNF- $\alpha$, IL-2, and IL-6, the cytokine 
receptor chain IL-2R- $\alpha$ or the IL-6R $80 \mathrm{kDa}$ chain impair their functionality. In contrast, cleavage of IL-8 by PR3 was shown to yield a more active form of this chemokine (125).

\section{Active pacification: How high density NETs promote resolution of inflammation}

The reason for the resolution of inflammation in gout in the persistent presence of high amounts of the initial irritant (MSU crystals) in the tissue was elusive until recently. Interestingly, we observed that MSU crystal-induced ROS-dependent NET-formation is accompanied by massive cytokine- and chemokine-release when only few neutrophils are present. In contrast, when neutrophils are present in high densities, similar to those found after continuous recruitment of granulocytes to an inflammation site, MSU crystal-induced NETs formed dense anti-inflammatory aggregates (aggNETs) (112).

AggNETs are composed of a meshwork of MSU crystals held together by NETs and are reminiscent of the pathognomonical structures of gout: tophi. These tophi are localized macroscopic lesions consisting of aggregates of MSU and several inflammatory cell types, mostly neutrophils and $\mathrm{CD} 8^{+}$cells $(14,126)$. They tend to accumulate on the subchondral bone, the subcutaneous tissue and next to tendons. We showed that tophi isolated from patients with gout share typical characteristics of NETs, such as extra-nuclear chromatin colocalizing with materials from neutrophil granules (112).

Unexpectedly, the concentrations of most cytokines and chemokines in high density cultures of neutrophils were decreased rather than elevated. AggNETs also actively lowered the concentrations of exogenously added inflammatory mediators $(14,115)$. We then examined the mechanism for this sequestration of cytokines and chemokines. Inhibition of transglutaminases did not show any effect, but blockade of PR3 and NE with elafin, suramin and sivelestat, or incubation with the serine proteinase inhibitor PMSF inhibited degradation by aggNETs of inflammatory mediators.

Aside of DNA and antimicrobial peptides, neutrophil proteases derived from azurophilic (primary) and specific (secondary) granules are a substantial constituent of NETs. Proteome analysis identified NE, cathepsin G, and PR3 in PMA-induced NETs, with NE being the most-abundant non-histone protein in NETs, and cathepsin G and PR3 reaching about $40 \%$ and $10 \%$ of the amount of NE, respectively (120). NE is also the major contributor to proteolytic NSPs activity within NETs. 
We propose that proteolytical degradation of pro-inflammatory mediators by high density NETs interrupts the self-amplifying circle of neutrophil recruitment and activation and is crucial for the resolution of neutrophil-driven inflammation (Fig. 2). In areas of low neutrophil densities (e.g., in blood or in affected tissues during early stages of gout), individual NETting neutrophils trap MSU crystals in an inflammatory manner, releasing their load of pro-inflammatory mediators. In lupus NETs may also serve as an important source of autoantigens, especially if their clearance is insufficient. In areas of high cell densities (e.g., in tissue infiltrates during late stages of gout or the pristane-injected peritoneum), the NETting neutrophils clump and form aggregates. The size and consistency of these aggregates varies depending on the physical and chemical nature of the trigger. Inducers of NET formation may be soluble (e.g., PMA), oily (e.g., pristane) or solid (e.g., crystals). Nevertheless they share the ability to capture and degrade inflammatory mediators by inherent proteases and thus initiate the resolution of inflammation.

\section{The relationship between neutrophil accumulation and NET formation}

During the last years the technological progress in two-photon intravital microscopy has enabled observation of neutrophils in vivo over extended periods of time. By this means a remarkable neutrophil behavior was discovered that is reminiscent of the swarming of insects and is therefore referred to as neutrophil swarming (127). At sites of tissue injury or infection, groups of neutrophils undergo highly coordinated series of movements, followed by cell accumulation and clustering (128). Neutrophil swarming was observed in several mouse models of tissue wounding, sterile inflammation, and infection and occurs in many mouse organs but also in human PMNs (129). Interestingly, cell death, both in the inflamed surrounding tissue and within the neutrophil cluster itself, seems to strongly influence swarming. The growth and persistence of swarms correlates to the size of the initial tissue damage, likely because the amount of neutrophil-attracting signals released by the damaged tissue is proportional to the size of the injury. Even neutrophil cell death alone can initiate swarming, suggesting that material from the lysed cell may attract other neutrophils (128). It is yet not clear which factors released by dying cells attract further neutrophils and induce swarming and clustering. ATP was suggested as one of these attracting molecules $(127,128)$. Interestingly, we observed ATP to also augment aggNET formation (14). It is tempting to hypothesize that neutrophil swarming and the formation of high density NETs are interdependent processes, but as for now, the connection between these cellular 
behaviors is elusive. A recent study showed that formation of swarms initiated by Alum is followed and augmented by NET formation (130). However, initial swarming did not seem to depend on NET formation. In our study we observed very quick aggregation of neutrophils in the presence of MSU crystals, which was however dependent on the ability to form NETs, since ROS-deficient neutrophils did not aggregate efficiently (14).

The accumulation of neutrophils in swarms and high density NETs is accompanied by advantages and disadvantages: the coordinated cell accumulation sequesters sites of inflammation from viable surrounding tissue and can function as a barrier preventing microbial invaders or other inflammatory triggers from spreading and causing havoc. On the downside, unlimited accumulation in swarms or aggNETs can damage tissue.

\section{NETs clog ducts - occlusion and barrier function by aggNETs}

Acute pancreatitis is a devastating disease neglected by most immunologists and cell death scientists (131), even though cell death mechanisms crucially determine the disease outcome and the concomitant fate of the patient (132). Acute pancreatitis may be instigated by diverse mechanisms including toxic (alcohol, drugs) and metabolic dysregulation (hypertriglyceridemia, hypercalcemia). The most common instigator, however, is the obstruction of the common biliopancreatic duct by bile stones or biliary sludge consisting of calcium carbonate, calcium bilirubinate or cholesterol crystals embedded in a viscous extracellular matrix of poorly characterized composition (133). In rare cases, pancreatitis may be due to immune-mediated mechanisms as in so-called "autoimmune pancreatitis" type 1 and 2 (134). The severity of acute pancreatitis varies widely: whereas edematous pancreatitis ( $80 \%$ of all cases) takes a benign course and is treated by mere fluid resuscitation, multi-organ failure and lethality are frequent in necrotizing pancreatitis (135, 136). For clinicians, it is most important to predict severe courses of disease to adapt the modalities of patient care and initiate organ replacement therapies in time. A better pathophysiological understanding of the disease is needed to improve patient care and develop new therapeutic strategies.

\section{Neutrophilic auto-inflammation of the pancreas}

In a recent study, we re-evaluated the function of neutrophils in pancreatitis and described a novel mechanism of pancreatitis induction by NETs. We observed pancreatitis and 
consequent fibrotic remodeling of the exocrine pancreas in two systems of transgenic IL17 A delivery (137). Delivery of IL-17A alone was capable of stimulating bone marrow granulopoiesis and mobilization of neutrophils to the circulation. Impressively, neutrophils almost selectively infiltrated the pancreas in large quantities without the administration of a specific local trigger. We further noticed that the infiltrating neutrophils did not remain in the interstitial part of the organ but also performed trans-epithelial migration leading to the formation of cellular aggregates inside the ductal lumen of the exocrine system of the pancreas. Interestingly, these intraductal aggregates were immunopositive for citrullinated histone $\mathrm{H} 3$, a hallmark of PAD4 activity and a signature of NETs. These observations led us to postulate several hypotheses:

I) Neutrophils are responsible for IL-17A-induced pancreatitis

II) The interaction of neutrophils with contents of the pancreatic ductal lumen determines the outcome of disease

III) Local triggers inside the pancreatic ductal lumen need to be responsible for histone citrullination and aggregated NET formation

IV) Aggregation of neutrophils inside the ductal lumen strongly impacts epithelial secretory function and flow

In order to test I), we made use of neutrophil depletion strategies in this novel model of IL17A-induced pancreatitis and, indeed, observed, that neutrophil depletion by anti-Ly6G antibodies abrogated the infiltration of the pancreas by further immune cells and abolished the remodeling of the exocrine pancreas. This highlighted that neutrophils cause the development of pancreatic fibrosis in this model. To approach II), we cultured human PMNs in human pancreatic juice or stimulated these cells with single characteristic components of pancreatic juice. The secretion of the exocrine pancreas is called pancreatic juice and consists of a calcium and bicarbonate-rich fluid further containing precursors of pancreatic digestive enzymes (trypsinogen, chymotrypsinogen), which are usually activated by enteropeptidase in the small intestinal lumen to enable digestive proteolysis. The constitution of the pancreatic juice varies when fasting or after meals and can contain as much as $150 \mathrm{mM}$ bicarbonate during the postprandial state to neutralize the $\mathrm{pH}$ of the duodenal content after gastric acidification. We observed that neutrophils extruded decondensed chromatin when cultured in human pancreatic juice. The extruded 
decondensed chromatin formed macroscopically visible aggregates inside the culture dish. To identify single components of the human pancreatic juice responsible for this effect, we cultured neutrophils in protease-free media with a similar ionic composition as the pancreatic juice. We observed that a disturbed ionic milieu with elevated levels of bicarbonate or reduced amounts of $\mathrm{pCO} 2$ and hence an alkaline-prone $\mathrm{pH}$, respectively, readily induced chromatin decondensation and externalization. We, therefore, identified the "ménage-à-trois" of bicarbonate, $\mathrm{pCO} 2$ and the $\mathrm{pH}$ as strong determinants of NET formation (138). Importantly, inhibition of PAD4 reduced the extent of chromatin decondensation by neutrophils cultured in media with slightly elevated bicarbonate levels. As recent studies including our own have implicated crystals as potential instigators of NET formation, we created calcium carbonate precipitations typical of pancreatic concrements. Pancreatic juice is supersaturated with calcium and bicarbonate which facilitates crystalization. Again, when stimulated by calcium carbonate crystals, human neutrophils underwent chromatin decondensation, externalization and aggregate formation. Aggregated NETs were subjected to immunocytochemistry and NE and citrullinated histones were readily detected in the aggregates stimulated by bicarbonate or calcium carbonate crystals. In essence, several components of the pancreatic juice induce neutrophil aggregation and NET formation characterized by citrullinated histone immunopositivity.

Interestingly, IL-17A induced granulocytosis and systemic mobilization of neutrophils in both wildtype and PAD4-deficient mice. However, infiltration of the pancreas by neutrophils and intraductal aggregates of neutrophils were selectively absent in PAD4-deficient mice. Hence, PAD4 activity is crucial for the development of neutrophil-mediated IL-17A-induced pancreatitis.

The pathophysiological chain of events in this model most closely resembles findings from the rare human disease autoimmune pancreatitis type 2 , which is characterized by pathognomonic granulocytic epithelial lesions (GELs) (139). This disease is typically associated with chronic inflammatory states like ulcerative colitis and responds readily to corticosteroid therapy (140).

\section{Ductal NETs in biliary pancreatitis}

We were, however, intrigued by the concept of trans-epithelial migration of neutrophils and consecutive aggregate formation and suspected a broader relevance of this phenomenon to 
the pathogenesis of glandular diseases and specifically pancreatitis. We hypothesized that NETs may be an important constituent of biliary sludge and thereby an inherent cause of acute biliary pancreatitis. NETs in biliary sludge might be an important constituent increasing sludge viscosity and amplifying its obstructive capability (Fig. 2).

Biliary pancreatitis is modeled by some groups by the retrograde infusion of sodium taurocholate into the biliopancreatic duct. Although this can be appreciated as a valid experimental system, one has to keep in mind, that obstructive pancreatitis also occurs without biliary reflux (141). We decided that a modified experimental approach of this technique could determine whether NETs in biliary sludge might contribute to ductal obstruction. As stated above, biliary sludge is characterized by precipitations of either calcium bilirubinate, calcium carbonate or cholesterol crystals. To address this experimentally, we placed calcium carbonate crystals inside the common biliopancreatic duct together with a suspension of murine neutrophils derived from either PAD4 knockout or wild-type mice in order to most closely model biliary sludge. Interestingly, the infusion of both calcium carbonate and neutrophils led to the formation of a duct-occluding mass immunopositive for citrullinated histone $\mathrm{H} 3$. The effect of these ductal instillations was most severe when both crystals and neutrophils were instillated, closely mimicking the effect of biliary sludge. Instillation of PAD4-deficient neutrophils reduced the damaging effect on the pancreatic parenchyma as compared to wild-type neutrophils.

\section{Walling off necrotic masses with NETs}

Once acute pancreatitis has taken a life-threatening necrotic turn of events, patients suffer from multi-organ failure (e.g. acute respiratory distress syndrome, kidney failure) and the abdominal cavity is characterized by a huge necrotic mass and saponification of the fatty tissue. These disease states may lead to long stays in intensive care units and long-term organ replacement therapies. As pancreatitis-specific causal therapies are lacking, the physicians need to wait for the necrotic mass to be encapsulated and walled-off by wound healing mechanisms of the patient's immune system. This may lead to the formation of walled-off necrotic material or so-called pseudocysts filled with pancreatic or inflammatory secretions (142). We identified NETs in pancreatic collections of patients with necrotizing pancreatitis. We speculated that neutrophils form a primary provisionary barrier in response to necrotic tissue by forming NETs. Making use of samples derived from autopsies of two 
cases of acute necrotizing pancreatitis we characterized the border of the necrotic tissue by immunohistochemistry (143). A layer of NE- and citrullinated histone H3-positive material surrounded the necrotic core and separated necrotic areas from viable tissue. A further example of the walling off areas of sterile necrotic by NETs was characterized by employing nanodiamonds below the critical size of $50 \mathrm{~nm}$. Injection of these particles in tissues causes local sterile necrosis accompanied by a neutrophil-driven initial inflammatory reaction that is promptly controlled by the subsequent formation of aggNETs (13). The aggressive nanodiamonds get sequestered and immobilized by the physical action of the aggNETs and the spreading of the inflammatory reaction gets dampened by the inactivation of chemokines by aggNETs.

This places the neutrophil at the center stage of the pathophysiology of conditions involving tissue necrosis like severe pancreatitis. In essence, neutrophils aim to contain an inflammatory focus. In the case of the walling-off of a necrotic tissue core this may have beneficial functions limiting the spread of toxic cellular debris. However, containment of an inflammatory focus by NETs is also enclosing ductal structures and occlusion by NETs will have detrimental consequences to dependent areas of the organ favoring secretory stasis, premature zymogen activation and consecutive auto-digestion (Fig. 2). In the case of biliary pancreatitis, accidental occlusion of the pancreatic duct may turn the beneficial containment of microcrystals to a toxic waste instigating deadly pancreatitis. In an independent study, Merza et al. have provided important additional clues to the role of NETs in severe acute pancreatitis by treating taurocholate-induced or arginine-induced pancreatitis with systemic DNase I, known to degrade NETs in vitro and in vivo (144). Interestingly, the authors noticed a beneficial effect of DNase-I treatment on severe acute pancreatitis. This effect was both visible locally, as DNase-I treatment reduced local tissue damage but also systemically as reduced lung toxicity was detected. Moreover, in the sera of patients suffering from acute pancreatitis elevated levels of cell-free DNA as well as single NET components were detected, implying that circulating NETs may take part in multi-organ damage in this deadly disease.

The discovery of NETs has substantially altered the concept of extracellular proteolysis, which is enormously relevant also in the field of pancreatic diseases. Usually, serine proteases of both neutrophil or pancreatic origin are subject to inhibition by ubiquitous serine protease inhibitors, such as alpha1-antitrypsin. Binding of serine proteases to DNA 
reduces the proteolytical activity of these enzymes. However, DNA-binding also protects serine proteases from alpha1-antitrypsin mediated inhibition and thus permits extracellular proteolysis. This observation may refine future strategies of protease inhibition for the treatment of pancreatitis (145). NET-directed therapies are already a mainstay of therapy of severe pancreatitis: removal of NET-enhanced ductal biliary sludge occlusion by endoscopic retrograde choledochopancreaticography (ERCP) is the backbone of treatment in biliary pancreatitis. Low-molecular weight heparin treatment capable of dismantling circulatory NETs possibly causative for multi-organ failure is provided to almost every single patient in the intensive care unit. Whether additional future NET-targeted therapies may improve the therapeutic outcome will be of outstanding interest.

Taken together, the anatomical localization of NETs strongly determines the respective function of NETs and their role in either containment, restitution, or unintended spread of the disease.

\section{When NETs occlude blood vessels}

Canonical hemostasis enables the rapid formation of blood clots at the site of vascular injury, prevents hemorrhage, and involves activation of platelets and fibrin strands. It is initiated by the exposure of subendothelial extracellular matrix (ECM) which binds von Willebrand factor (VWF) and recruits circulating platelets that aggregate and form a plug. In parallel, the extrinsic arm of the coagulation cascade is initiated by tissue factor (TF), a membrane bound endothelial glycoprotein that activates thrombin and fibrin. A plethora of endogenous plasmatic anticoagulants or fibrinolytic proteins tightly control this process. Thrombosis, intravascular blood clotting, is the pathologic counterpart to hemostasis. Thrombosis shares the principle steps of hemostasis, but engages additionally the clotting Factor XII-driven intrinsic coagulation cascade (146). Furthermore, thrombosis closely partners with inflammation and thus may be referred to as "immunothrombosis" (147-149). The contribution of NETs to this cooperation has been documented in several animal models (150). The principal studies analysed the function of NETs in thrombosis by two therapeutic strategies: blocking NETosis by interfering with PAD4 and/or NE activity or infusion of DNase1 or anti-DNA-antibodies to neutralize NETs. In arterial thrombosis triggered by dysfunctional endothelia, a fast and platelet-dependent process, NETs promoted formation of stable occlusive thrombi $(98,151)$. In venous thrombosis due to 
disturbances in blood flow, a slow process driven by fibrin formation, DNase1 infusion or PAD4-deficiency reduced thrombus formation (152-154). In mice prone to develop atherosclerosis, the inhibition of NETosis or the therapeutic DNases reduced atherosclerotic lesions and vascular occlusions $(155,156)$. Furthermore, a murine model of cancer-induced microvascular thrombosis, infusion of DNase1 reduced systemically blood hypercoagulability (157). The precise mechanism how NETs contribute to vascular occlusions in vivo is poorly understood, but in vitro experiments suggest that NETs may promote thrombosis by several means. NETs provide a scaffold for the adhesion of blood cells, including platelets and erythrocytes (158). Whether the adhesion to NETs is mediated by entrapment, electrostatic affinity or via a receptor-ligand interaction is elusive. NETs interact with von Willebrand Factor (VVWF), an adhesion molecule released by activated endothelia. A protein domain of endothelial VWF interacts with chromatin and may thus immobilize NETs onto the vascular endothelia $(159,160)$. NETs interact with the plasma clotting factors. NETs stimulate the extrinsic pathway through activating tissue factor (151, 154) inactivating tissue factor pathway inhibitor (151). The intrinsic pathway is initiated by activation of FXII on negatively charged surfaces. NETs bind Factor XII and NET-DNA provides a negatively charged scaffold that activates FXII $(154,161)$. Furthermore, in vitro blood clots with NETs are partially resistant to plasmin-mediated-induced thrombolysis, suggesting that NETs may provide an alternative scaffold to fibrin (158). In summary, NETs contribute to thrombosis possibly through interactions with the vascular endothelium, blood cells, and clotting factors. It is noteworthy that despite the established antithrombotic effect of DNase1 infusion and PAD4 inhibition, neither measure interferes with hemostasis. Thus targeting of NETs may provide safe therapeutic strategy for thrombosis and its associated diseases.

\section{Acknowledgements}

This work was partially funded by the Volkswagen-Stiftung, by MSD Sharpe \& Dohme $\mathrm{GmbH}$, by the German Research Foundation (DFG, CRC1181-C03, KFO257, FU 741/4-1, INST 152/692), by the EU H2020-MSCE-RISE-2015 projects Nr. 690836 PANG and 644035 REDOXIT, by the Interdisziplinäres Zentrum für klinische Forschung (IZKF) and by the ELAN fonds of the University of Erlangen-Nürnberg. 


\section{Conflict of interest}

The authors declare that there is no conflict of interest. 
Table 1. Frequency and distribution of hematoxylin bodies in three systematic necropsy studies of patients with Systemic Lupus Erythematosus.

\begin{tabular}{lccccccc}
\hline Study & Klemperer 1950 & Gueft 1954 & Worthington 1959 & Total \\
\hline Patients (n) & 35 & & 14 & & 20 & & 69 \\
Disease Controls (n) & n.s. & & 50 & & 50 & & 100 \\
\hline Organ & $\mathbf{n}$ & $\%$ & $\mathbf{n}$ & $\%$ & $\mathbf{n}$ & $\%$ & Mean \% \\
\hline Heart & 21 & 60 & 11 & 79 & 15 & 75 & 77 \\
Kidney & 27 & 77 & 13 & 93 & 12 & 60 & 76 \\
LN and Spleen & 17 & 49 & 12 & 86 & 7 & 35 & 60 \\
Ovary & 13 & 37 & 9 & 64 & 9 & 45 & 55 \\
Serosal Membranes & 5 & 14 & 6 & 43 & 6 & 30 & 36 \\
Liver & 1 & 3 & 3 & 21 & 2 & 10 & 11 \\
Pancreas & 1 & 3 & 3 & 21 & 1 & 5 & 10 \\
Bone Marrow & 1 & 3 & 2 & 14 & & 0 & 9 \\
In two or more organs & 24 & 69 & 13 & 93 & 17 & 85 & 82 \\
\hline Overall & 32 & 91 & 13 & 93 & 17 & 85 & 90 \\
\hline
\end{tabular}


Figure 1

Homeostatic apoptosis in patients with SLE
in germinal centers in peripheral tissues

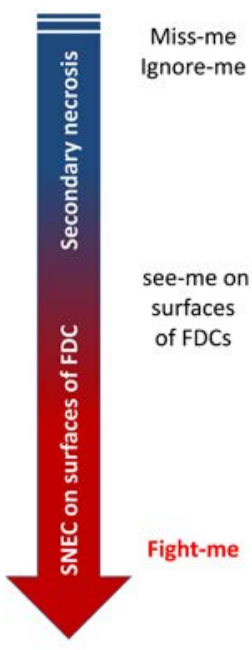

Pathologic autoimmunity in patients with SLE

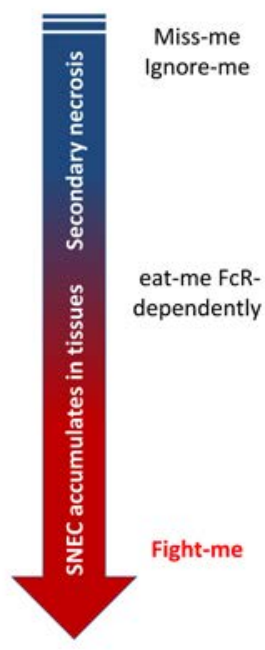

Pathologic inflammation in patients with SLE

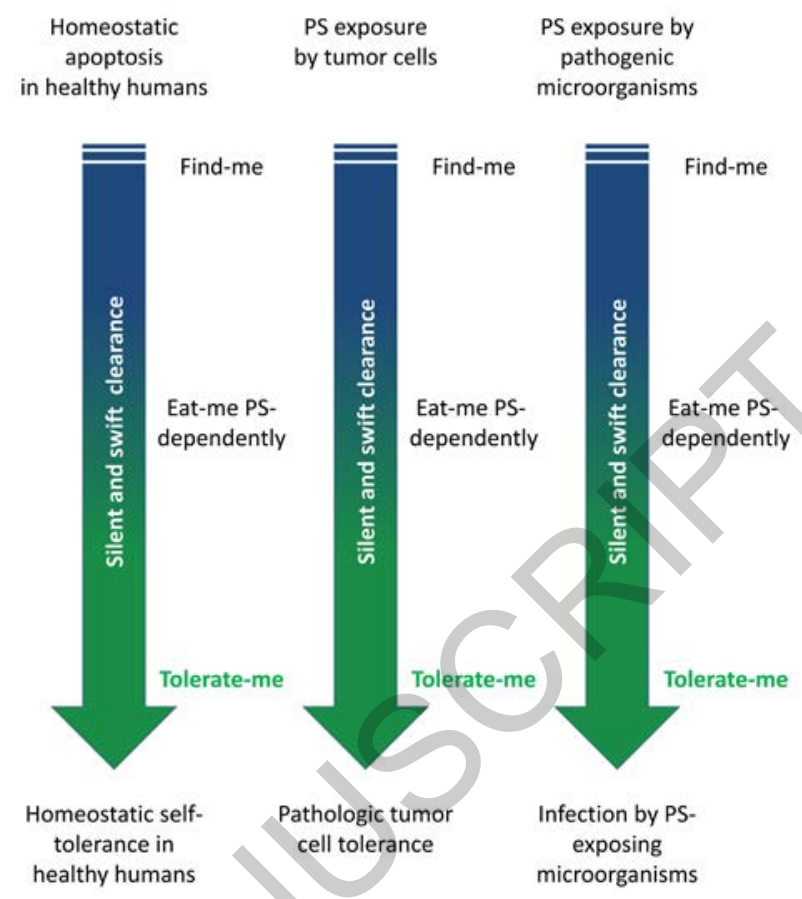

Figure 1. The progression of the clearance of apoptotic cells determines the final meaning of cell death. Homeostatic apoptosis usually derives in the promotion of self-tolerance in healthy individuals. When find-me and eat-me signals fail, the clearance progress towards the generation of autoimmunity and the precipitation of inflammation. In some cases, the mechanisms of tolerance are hijacked by microorganisms or tumors to evade the action of the immune system. 
Figure 2

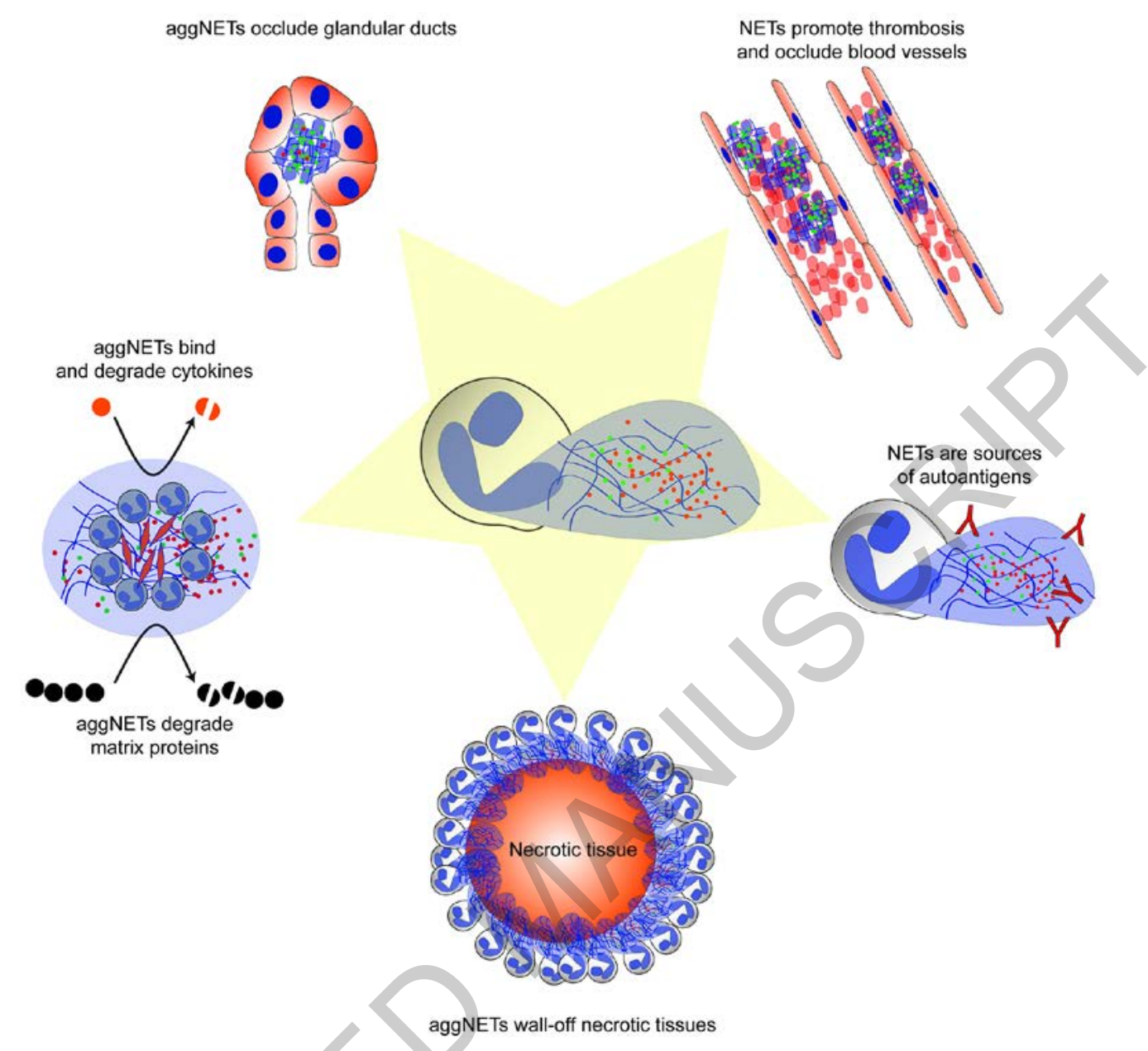

Figure 2. Consequences of NET formation in sterile diseases

Neutrophil extracellular traps (NETs) form in response to various stimuli (e.g. microparticles (162) or crystals (14), disturbed ionic milieu (138) or necrotic tissue $(13,107))$. The aim of neutrophils in sterile diseases is containment of danger and injury. This can be achieved by means of a neutrophil and NET barrier around necrotic tissues or foreign bodies/crystals. NETs come at the price of collateral tissue damage induced by highly basic proteins and NET-bound protease-mediated matrix degradation (163-165), but also contribute to dampening of inflammation by functioning as a cytokine sink (binding and degradation) (14, 115). NETs can aggregate to macroscopically visible clusters (aggNETs) dependent on the amount of neutrophils needed for containment. This may induce the occlusion of ductal structures: blood vessels or glandular ducts, respectively $(137,158)$. NETs carry antigens of autoantibodies in SLE and small-vessel vasculitis and represent a structural platform for immune complex formation in these rheumatic diseases $(93,95)$. 


\section{References}

1. Herrmann M, Voll RE, Zoller OM, Hagenhofer M, Ponner BB, Kalden JR. Impaired phagocytosis of apoptotic cell material by monocyte-derived macrophages from patients with systemic lupus erythematosus. Arthritis Rheum. 1998;41(7):1241-50.

2. Gaipl US, Munoz LE, Grossmayer G, et al. Clearance deficiency and systemic lupus erythematosus (SLE). J Autoimmun. 2007;28(2-3):114-21.

3. Kerr JF, Wyllie AH, Currie AR. Apoptosis: a basic biological phenomenon with wideranging implications in tissue kinetics. British journal of cancer. 1972;26(4):239-57.

4. Voll RE, Herrmann M, Roth EA, Stach C, Kalden JR, Girkontaite I. Immunosuppressive effects of apoptotic cells. Nature. 1997;390(6658):350-1.

5. Stach CM, Turnay $X$, Voll RE, et al. Treatment with annexin $V$ increases immunogenicity of apoptotic human T-cells in Balb/c mice. Cell death and differentiation. 2000;7(10):911-5.

6. Gaipl US, Voll RE, Sheriff A, Franz S, Kalden JR, Herrmann M. Impaired clearance of dying cells in systemic lupus erythematosus. Autoimmun Rev. 2005;4(4):189-94.

7. Kinchen JM, Ravichandran KS. Journey to the grave: signaling events regulating removal of apoptotic cells. Journal of cell science. 2007;120(Pt 13):2143-9.

8. Weichand B, Weis N, Weigert A, Grossmann N, Levkau B, Brune B. Apoptotic cells enhance sphingosine-1-phosphate receptor 1 dependent macrophage migration. European journal of immunology. 2013;43(12):3306-13.

9. Lauber K, Bohn E, Krober SM, et al. Apoptotic cells induce migration of phagocytes via caspase-3-mediated release of a lipid attraction signal. Cell. 2003;113(6):717-30.

10. Truman LA, Ford CA, Pasikowska $M$, et al. CX3CL1/fractalkine is released from apoptotic lymphocytes to stimulate macrophage chemotaxis. Blood. 2008;112(13):5026-36.

11. Peter C, Wesselborg S, Herrmann M, Lauber K. Dangerous attraction: phagocyte recruitment and danger signals of apoptotic and necrotic cells. Apoptosis : an international journal on programmed cell death. 2010;15(9):1007-28.

12. Bournazou I, Pound JD, Duffin R, et al. Apoptotic human cells inhibit migration of granulocytes via release of lactoferrin. The Journal of clinical investigation. 2009;119(1):2032.

13. Biermann MH, Podolska MJ, Knopf J, et al. Oxidative Burst-Dependent NETosis Is Implicated in the Resolution of Necrosis-Associated Sterile Inflammation. Frontiers in immunology. 2016;7:557.

14. Schauer C, Janko C, Munoz LE, et al. Aggregated neutrophil extracellular traps limit inflammation by degrading cytokines and chemokines. Nature medicine. 2014;20(5):511-7.

15. Meesmann HM, Fehr EM, Kierschke $S$, et al. Decrease of sialic acid residues as an eat-me signal on the surface of apoptotic lymphocytes. Journal of cell science. 2010;123(Pt 19):3347-56.

16. Appelt U, Sheriff A, Gaipl US, Kalden JR, Voll RE, Herrmann M. Viable, apoptotic and necrotic monocytes expose phosphatidylserine: cooperative binding of the ligand 
Annexin $\mathrm{V}$ to dying but not viable cells and implications for PS-dependent clearance. Cell death and differentiation. 2005;12(2):194-6.

17. Janko $\mathrm{C}$, Jeremic I, Biermann $\mathrm{M}$, et al. Cooperative binding of Annexin A5 to phosphatidylserine on apoptotic cell membranes. Physical biology. 2013;10(6):065006.

18. Biermann M, Maueroder C, Brauner JM, et al. Surface code--biophysical signals for apoptotic cell clearance. Physical biology. 2013;10(6):065007.

19. Lauber K, Keppeler H, Munoz LE, et al. Milk fat globule-EGF factor 8 mediates the enhancement of apoptotic cell clearance by glucocorticoids. Cell death and differentiation. 2013;20(9):1230-40.

20. Chaurio RA, Janko C, Munoz LE, Frey B, Herrmann M, Gaipl US. Phospholipids: key players in apoptosis and immune regulation. Molecules. 2009;14(12):4892-914.

21. Biermann $\mathrm{MH}$, Veissi $\mathrm{S}$, Maueroder $\mathrm{C}$, et al. The role of dead cell clearance in the etiology and pathogenesis of systemic lupus erythematosus: dendritic cells as potential targets. Expert review of clinical immunology. 2014;10(9):1151-64.

22. Fairn GD, Grinstein S. How nascent phagosomes mature to become phagolysosomes. Trends in immunology. 2012;33(8):397-405.

23. Uderhardt S, Herrmann M, Oskolkova OV, et al. 12/15-lipoxygenase orchestrates the clearance of apoptotic cells and maintains immunologic tolerance. Immunity. 2012;36(5):834-46.

24. Ipseiz N, Uderhardt S, Scholtysek $\mathrm{C}$, et al. The nuclear receptor Nr4a1 mediates anti-inflammatory effects of apoptotic cells. Journal of immunology. 2014;192(10):4852-8.

25. Munoz LE, Lauber K, Schiller M, Manfredi AA, Herrmann M. The role of defective clearance of apoptotic cells in systemic autoimmunity. Nature reviews Rheumatology. 2010;6(5):280-9.

26. Birge RB, Boeltz $S$, Kumar $S$, et al. Phosphatidylserine is a global immunosuppressive signal in efferocytosis, infectious disease, and cancer. Cell death and differentiation. 2016;23(6):962-78.

27. van Zandbergen G, Bollinger A, Wenzel A, et al. Leishmania disease development depends on the presence of apoptotic promastigotes in the virulent inoculum. Proceedings of the National Academy of Sciences of the United States of America. 2006;103(37):1383742.

28. Franz S, Frey B, Sheriff A, et al. Lectins detect changes of the glycosylation status of plasma membrane constituents during late apoptosis. Cytometry Part $A$ : the journal of the International Society for Analytical Cytology. 2006;69(4):230-9.

29. Franz S, Herrmann K, Furnrohr BG, et al. After shrinkage apoptotic cells expose internal membrane-derived epitopes on their plasma membranes. Cell death and differentiation. 2007;14(4):733-42.

30. Bilyy RO, Shkandina T, Tomin A, et al. Macrophages discriminate glycosylation patterns of apoptotic cell-derived microparticles. The Journal of biological chemistry. 2012;287(1):496-503. 
31. Frey $B$, Munoz LE, Pausch $F$, et al. The immune reaction against allogeneic necrotic cells is reduced in Annexin A5 knock out mice whose macrophages display an antiinflammatory phenotype. Journal of cellular and molecular medicine. 2009;13(7):1391-9.

32. Frey B, Schildkopf $\mathrm{P}$, Rodel $\mathrm{F}$, et al. AnnexinA5 renders dead tumor cells immunogenic--implications for multimodal cancer therapies. Journal of immunotoxicology. 2009;6(4):209-16.

33. Bondanza A, Zimmermann VS, Rovere-Querini $P$, et al. Inhibition of phosphatidylserine recognition heightens the immunogenicity of irradiated lymphoma cells in vivo. The Journal of experimental medicine. 2004;200(9):1157-65.

34. Munoz LE, Franz S, Pausch F, et al. The influence on the immunomodulatory effects of dying and dead cells of Annexin V. Journal of leukocyte biology. 2007;81(1):6-14.

35. Galluzzi L, Buque A, Kepp O, Zitvogel L, Kroemer G. Immunogenic cell death in cancer and infectious disease. Nature reviews Immunology. 2017;17(2):97-111.

36. Chaurio RA, Munoz LE, Maueroder C, et al. The progression of cell death affects the rejection of allogeneic tumors in immune-competent mice - implications for cancer therapy. Frontiers in immunology. 2014;5:560.

37. Maueroder C, Chaurio RA, Dumych T, et al. A blast without power - cell death induced by the tuberculosis-necrotizing toxin fails to elicit adequate immune responses. Cell death and differentiation. 2016;23(6):1016-25.

38. Scaffidi P, Misteli T, Bianchi ME. Release of chromatin protein HMGB1 by necrotic cells triggers inflammation. Nature. 2002;418(6894):191-5.

39. Urbonaviciute $\mathrm{V}$, Furnrohr BG, Meister $\mathrm{S}$, et al. Induction of inflammatory and immune responses by HMGB1-nucleosome complexes: implications for the pathogenesis of SLE. The Journal of experimental medicine. 2008;205(13):3007-18.

40. Svensson B. Occurrence of deficient monocyte yeast cell phagocytosis in presence of rheumatic sera. Scandinavian journal of rheumatology Supplement. 1980;31:21-7.

41. Munoz LE, Chaurio RA, Gaipl US, Schett G, Kern P. MoMa from patients with systemic lupus erythematosus show altered adhesive activity. Autoimmunity. 2009;42(4):269-71.

42. Cairns AP, Crockard AD, McConnell JR, Courtney PA, Bell AL. Reduced expression of CD44 on monocytes and neutrophils in systemic lupus erythematosus: relations with apoptotic neutrophils and disease activity. Annals of the rheumatic diseases. 2001;60(10):950-5.

43. Munoz LE, Frey B, Appelt U, et al. Peripheral Blood Stem Cells of Patients with Systemic Lupus Erythematosus Show Altered Differentiation into Macrophages. The Open Autoimmunity Journal. 2010;2:11-6.

44. Winkler TH, Fehr H, Kalden JR. Analysis of immunoglobulin variable region genes from human IgG anti-DNA hybridomas. European journal of immunology. 1992;22(7):171928.

45. Wellmann $U$, Letz $M$, Herrmann $M$, Angermuller S, Kalden JR, Winkler TH. The evolution of human anti-double-stranded DNA autoantibodies. Proceedings of the National Academy of Sciences of the United States of America. 2005;102(26):9258-63. 
46. Baumann I, Kolowos W, Voll RE, et al. Impaired uptake of apoptotic cells into tingible body macrophages in germinal centers of patients with systemic lupus erythematosus. Arthritis Rheum. 2002;46(1):191-201.

47. Schulze C, Munoz LE, Franz S, et al. Clearance deficiency--a potential link between infections and autoimmunity. Autoimmun Rev. 2008;8(1):5-8.

48. Rosen A, Casciola-Rosen L, Ahearn J. Novel packages of viral and self-antigens are generated during apoptosis. The Journal of experimental medicine. 1995;181(4):1557-61.

49. Manfredi AA, Rovere P, Galati G, et al. Apoptotic cell clearance in systemic lupus erythematosus. I. Opsonization by antiphospholipid antibodies. Arthritis Rheum. 1998;41(2):205-14.

50. Zabaleta-Lanz ME, Munoz LE, Tapanes FJ, et al. Further description of early clinically silent lupus nephritis. Lupus. 2006;15(12):845-51.

51. Chen J, Carey K, Godowski PJ. Identification of Gas6 as a ligand for Mer, a neural cell adhesion molecule related receptor tyrosine kinase implicated in cellular transformation. Oncogene. 1997;14(17):2033-9.

52. Cohen PL, Caricchio R, Abraham V, et al. Delayed apoptotic cell clearance and lupus-like autoimmunity in mice lacking the c-mer membrane tyrosine kinase. The Journal of experimental medicine. 2002;196(1):135-40.

53. Hanayama R, Tanaka M, Miyasaka $\mathrm{K}$, et al. Autoimmune disease and impaired uptake of apoptotic cells in MFG-E8-deficient mice. Science. 2004;304(5674):1147-50.

54. Seredkina N, Rekvig OP. Acquired loss of renal nuclease activity is restricted to DNasel and is an organ-selective feature in murine lupus nephritis. Am J Pathol. 2011;179(3):1120-8.

55. Yoshida H, Okabe $\mathrm{Y}$, Kawane K, Fukuyama H, Nagata S. Lethal anemia caused by interferon-beta produced in mouse embryos carrying undigested DNA. Nature immunology. 2005;6(1):49-56.

56. Kawane K, Ohtani M, Miwa K, et al. Chronic polyarthritis caused by mammalian DNA that escapes from degradation in macrophages. Nature. 2006;443(7114):998-1002.

57. Quartier P, Potter PK, Ehrenstein MR, Walport MJ, Botto M. Predominant role of IgMdependent activation of the classical pathway in the clearance of dying cells by murine bone marrow-derived macrophages in vitro. European journal of immunology. 2005;35(1):252-60.

58. Zhuang H, Han S, Li Y, et al. A Novel Mechanism for Generating the Interferon Signature in Lupus: Opsonization of Dead Cells by Complement and IgM. Arthritis \& rheumatology. 2016;68(12):2917-28.

59. Leffler J, Bengtsson AA, Blom AM. The complement system in systemic lupus erythematosus: an update. Annals of the rheumatic diseases. 2014;73(9):1601-6.

60. Gaipl US, Beyer TD, Heyder P, et al. Cooperation between C1q and DNase I in the clearance of necrotic cell-derived chromatin. Arthritis Rheum. 2004;50(2):640-9.

61. Jonsson G, Sjoholm AG, Truedsson L, Bengtsson AA, Braconier JH, Sturfelt G. Rheumatological manifestations, organ damage and autoimmunity in hereditary C2 deficiency. Rheumatology. 2007;46(7):1133-9. 
62. Yang $\mathrm{Y}$, Chung EK, $\mathrm{Wu} \mathrm{YL}$, et al. Gene copy-number variation and associated polymorphisms of complement component $\mathrm{C} 4$ in human systemic lupus erythematosus (SLE): low copy number is a risk factor for and high copy number is a protective factor against SLE susceptibility in European Americans. American journal of human genetics. 2007;80(6):1037-54.

63. Alegretti AP, Schneider L, Piccoli AK, et al. Diminished expression of complement regulatory proteins on peripheral blood cells from systemic lupus erythematosus patients. Clinical \& developmental immunology. 2012;2012:725684.

64. Toller-Kawahisa JE, Vigato-Ferreira IC, Pancoto JA, et al. The variant of CD11b, rs1143679 within ITGAM, is associated with systemic lupus erythematosus and clinical manifestations in Brazilian patients. Human immunology. 2014;75(2):119-23.

65. Du Clos TW, Zlock LT, Rubin RL. Analysis of the binding of C-reactive protein to histones and chromatin. Journal of immunology. 1988;141(12):4266-70.

66. Jewell WS, Marnell LL, Rokeach LA, Du Clos TW. C-reactive protein (CRP) binding to the Sm-D protein of snRNPS. Identification of a short polypeptide binding region. Molecular immunology. 1993;30(8):701-8.

67. Janko C, Franz S, Munoz LE, et al. CRP/anti-CRP antibodies assembly on the surfaces of cell remnants switches their phagocytic clearance toward inflammation. Frontiers in immunology. 2011;2:70.

68. Janko C, Schorn C, Weidner D, et al. Treatment with DNAse I fosters binding to nec PBMC of CRP. Autoimmunity. 2009;42(4):286-8.

69. Zandman-Goddard G, Blank M, Langevitz $P$, et al. Anti-serum amyloid component $P$ antibodies in patients with systemic lupus erythematosus correlate with disease activity. Annals of the rheumatic diseases. 2005;64(12):1698-702.

70. Munoz LE, Janko C, Chaurio RA, Schett G, Gaipl US, Herrmann M. IgG opsonized nuclear remnants from dead cells cause systemic inflammation in SLE. Autoimmunity. 2010;43(3):232-5.

71. Gross L. The cardiac lesions in Libman-Sacks disease: With a consideration of its relationship to acute diffuse lupus erythematosus. Am J Pathol. 1940;16(4):375-408 11.

72. Gueft B, Laufer A. Further cytochemical studies in systemic lupus erythematosus. AMA Arch Pathol. 1954;57(3):201-26.

73. Klemperer P, Gueft B, Lee S, Leuchtenberger C, Pollister A. Cytochemical changes of acute lupus erythematosus. Arch Pathol. 1950;49(5):503-16.

74. Worthington JW, Jr., Baggenstoss AH, Hargraves MM. Significance of hematoxylin bodies in the necropsy diagnosis of systemic lupus erythematosus. Am J Pathol. 1959;35:955-69.

75. Merrell M, Shulman LE. Determination of prognosis in chronic disease, illustrated by systemic lupus erythematosus. Journal of chronic diseases. 1955;1(1):12-32.

76. Pieterse E, van der Vlag J. Breaking Immunological Tolerance in Systemic Lupus Erythematosus. Frontiers in immunology. 2014;5:164. 
77. Sarmiento LF, Munoz LE, Chirinos P, Bianco NE, Zabaleta-Lanz ME. Opsonization by anti-dsDNA antibodies of apoptotic cells in systemic lupus erythematosus. Autoimmunity. 2007;40(4):337-9.

78. Grossmayer GE, Munoz LE, Weber CK, et al. IgG autoantibodies bound to surfaces of necrotic cells and complement $\mathrm{C} 4$ comprise the phagocytosis promoting activity for necrotic cells of systemic lupus erythaematosus sera. Annals of the rheumatic diseases. 2008;67(11):1626-32.

79. Janko C, Schorn C, Grossmayer GE, et al. Inflammatory clearance of apoptotic remnants in systemic lupus erythematosus (SLE). Autoimmun Rev. 2008;8(1):9-12.

80. Munoz LE, Janko C, Grossmayer GE, et al. Remnants of secondarily necrotic cells fuel inflammation in systemic lupus erythematosus. Arthritis Rheum. 2009;60(6):1733-42.

81. Sjowall C, Zapf J, von Lohneysen S, et al. Altered glycosylation of complexed native IgG molecules is associated with disease activity of systemic lupus erythematosus. Lupus. 2015;24(6):569-81.

82. Fickentscher C, Magorivska I, Janko C, et al. The Pathogenicity of Anti-beta2GP1IgG Autoantibodies Depends on Fc Glycosylation. Journal of immunology research. 2015;2015:638129.

83. Magorivska I, Munoz LE, Janko C, et al. Sialylation of anti-histone immunoglobulin G autoantibodies determines their capabilities to participate in the clearance of late apoptotic cells. Clinical and experimental immunology. 2016;184(1):110-7.

84. Pfeifle R, Rothe T, Ipseiz N, et al. Regulation of autoantibody activity by the IL-23TH17 axis determines the onset of autoimmune disease. Nature immunology. 2017;18(1):104-13.

85. Lovgren T, Eloranta ML, Bave U, Alm GV, Ronnblom L. Induction of interferon-alpha production in plasmacytoid dendritic cells by immune complexes containing nucleic acid released by necrotic or late apoptotic cells and lupus IgG. Arthritis Rheum. 2004;50(6):1861-72.

86. Brinkmann V, Reichard U, Goosmann C, et al. Neutrophil extracellular traps kill bacteria. Science. 2004;303(5663):1532-5.

87. Fuchs TA, Abed U, Goosmann C, et al. Novel cell death program leads to neutrophil extracellular traps. The Journal of cell biology. 2007;176(2):231-41.

88. Hoppenbrouwers T, Autar ASA, Sultan AR, et al. In vitro induction of NETosis: Comprehensive live imaging comparison and systematic review. PloS one. 2017;12(5):e0176472.

89. Neeli I, Radic M. Opposition between PKC isoforms regulates histone deimination and neutrophil extracellular chromatin release. Frontiers in immunology. 2013;4:38.

90. Yousefi S, Simon HU. NETosis - Does It Really Represent Nature's "Suicide Bomber"? Frontiers in immunology. 2016;7:328.

91. Yipp BG, Kubes P. NETosis: how vital is it? Blood. 2013;122(16):2784-94.

92. Smith CK, Kaplan MJ. The role of neutrophils in the pathogenesis of systemic lupus erythematosus. Current opinion in rheumatology. 2015;27(5):448-53. 
93. Lande R, Ganguly D, Facchinetti V, et al. Neutrophils activate plasmacytoid dendritic cells by releasing self-DNA-peptide complexes in systemic lupus erythematosus. Science translational medicine. 2011;3(73):73ra19.

94. Kienhofer D, Hahn J, Schubert I, et al. No evidence of pathogenic involvement of cathelicidins in patient cohorts and mouse models of lupus and arthritis. Plos one. 2014;9(12):e115474.

95. Hakkim A, Furnrohr BG, Amann K, et al. Impairment of neutrophil extracellular trap degradation is associated with lupus nephritis. Proceedings of the National Academy of Sciences of the United States of America. 2010;107(21):9813-8.

96. Corsiero E, Pratesi F, Prediletto E, Bombardieri M, Migliorini P. NETosis as Source of Autoantigens in Rheumatoid Arthritis. Frontiers in immunology. 2016;7:485.

97. Jorch SK, Kubes P. An emerging role for neutrophil extracellular traps in noninfectious disease. Nature medicine. 2017;23(3):279-87.

98. Knight JS, Zhao W, Luo W, et al. Peptidylarginine deiminase inhibition is immunomodulatory and vasculoprotective in murine lupus. The Journal of clinical investigation. 2013;123(7):2981-93.

99. Chumanevich AA, Causey CP, Knuckley BA, et al. Suppression of colitis in mice by Cl-amidine: a novel peptidylarginine deiminase inhibitor. American journal of physiology Gastrointestinal and liver physiology. 2011;300(6):G929-38.

100. Willis VC, Banda NK, Cordova KN, et al. Protein arginine deiminase 4 inhibition is sufficient for the amelioration of collagen-induced arthritis. Clinical and experimental immunology. 2017;188(2):263-74.

101. Wei L, Wasilewski E, Chakka SK, Bello AM, Moscarello MA, Kotra LP. Novel inhibitors of protein arginine deiminase with potential activity in multiple sclerosis animal model. Journal of medicinal chemistry. 2013;56(4):1715-22.

102. Baehner RL, Karnovsky ML. Deficiency of reduced nicotinamide-adenine dinucleotide oxidase in chronic granulomatous disease. Science. 1968;162(3859):1277-9.

103. De Ravin SS, Naumann N, Cowen EW, et al. Chronic granulomatous disease as a risk factor for autoimmune disease. The Journal of allergy and clinical immunology. 2008;122(6):1097-103.

104. Papayannopoulos V, Metzler KD, Hakkim A, Zychlinsky A. Neutrophil elastase and myeloperoxidase regulate the formation of neutrophil extracellular traps. The Journal of cell biology. 2010;191(3):677-91.

105. Roberts $\mathrm{H}$, White $\mathrm{P}$, Dias I, et al. Characterization of neutrophil function in PapillonLefevre syndrome. Journal of leukocyte biology. 2016;100(2):433-44.

106. Tekin B, Yucelten D, Beleggia F, Sarig O, Sprecher E. Papillon-Lefevre syndrome: report of six patients and identification of a novel mutation. International journal of dermatology. 2016;55(8):898-902.

107. Kienhofer D, Hahn J, Stoof J, et al. Experimental lupus is aggravated in mouse strains with impaired induction of neutrophil extracellular traps. JCl insight. 2017;2(10). 
108. Campbell AM, Kashgarian M, Shlomchik MJ. NADPH oxidase inhibits the pathogenesis of systemic lupus erythematosus. Science translational medicine. 2012;4(157):157ra41.

109. Kelkka T, Kienhofer D, Hoffmann M, et al. Reactive oxygen species deficiency induces autoimmunity with type 1 interferon signature. Antioxidants \& redox signaling. 2014;21(16):2231-45.

110. Calvani N, Caricchio R, Tucci M, et al. Induction of apoptosis by the hydrocarbon oil pristane: implications for pristane-induced lupus. Journal of immunology. 2005;175(7):477782.

111. Herman S, Fischer A, Presumey J, et al. Inhibition of Inflammation and Bone Erosion by RNA Interference-Mediated Silencing of Heterogeneous Nuclear RNP A2/B1 in Two Experimental Models of Rheumatoid Arthritis. Arthritis \& rheumatology. 2015;67(9):2536-46.

112. Holmdahl R, Sareila O, Olsson LM, Backdahl L, Wing K. Ncf1 polymorphism reveals oxidative regulation of autoimmune chronic inflammation. Immunological reviews. 2016;269(1):228-47.

113. Li P, Li M, Lindberg MR, Kennett MJ, Xiong N, Wang Y. PAD4 is essential for antibacterial innate immunity mediated by neutrophil extracellular traps. The Journal of experimental medicine. 2010;207(9):1853-62.

114. Gordon RA, Herter JM, Rosetti F, et al. Lupus and proliferative nephritis are PAD4 independent in murine models. JCl insight. 2017;2(10).

115. Reinwald C, Schauer C, Csepregi JZ, et al. Reply to "Neutrophils are not required for resolution of acute gouty arthritis in mice". Nature medicine. 2016;22(12):1384-6.

116. Schorn C, Frey B, Lauber $\mathrm{K}$, et al. Sodium overload and water influx activate the NALP3 inflammasome. The Journal of biological chemistry. 2011;286(1):35-41.

117. Schorn C, Janko C, Latzko M, Chaurio R, Schett G, Herrmann M. Monosodium urate crystals induce extracellular DNA traps in neutrophils, eosinophils, and basophils but not in mononuclear cells. Frontiers in immunology. 2012;3:277.

118. Mitroulis I, Kambas K, Chrysanthopoulou A, et al. Neutrophil extracellular trap formation is associated with IL-1beta and autophagy-related signaling in gout. PloS one. 2011;6(12):e29318.

119. Schorn C, Strysio M, Janko C, Munoz LE, Schett G, Herrmann M. The uptake by blood-borne phagocytes of monosodium urate is dependent on heat-labile serum factor(s) and divalent cations. Autoimmunity. 2010;43(3):236-8.

120. Alfaro C, Teijeira A, Onate C, et al. Tumor-Produced Interleukin-8 Attracts Human Myeloid-Derived Suppressor Cells and Elicits Extrusion of Neutrophil Extracellular Traps (NETs). Clinical cancer research : an official journal of the American Association for Cancer Research. 2016;22(15):3924-36.

121. Sagiv JY, Michaeli J, Assi S, et al. Phenotypic diversity and plasticity in circulating neutrophil subpopulations in cancer. Cell reports. 2015;10(4):562-73.

122. Carmona-Rivera C, Kaplan MJ. Low-density granulocytes: a distinct class of neutrophils in systemic autoimmunity. Seminars in immunopathology. 2013;35(4):455-63. 
123. Treffers LW, Hiemstra IH, Kuijpers TW, van den Berg TK, Matlung HL. Neutrophils in cancer. Immunological reviews. 2016;273(1):312-28.

124. Le Blanc K, Mougiakakos D. Multipotent mesenchymal stromal cells and the innate immune system. Nature reviews Immunology. 2012;12(5):383-96.

125. Shpacovitch V, Feld M, Hollenberg MD, Luger TA, Steinhoff M. Role of proteaseactivated receptors in inflammatory responses, innate and adaptive immunity. Journal of leukocyte biology. 2008;83(6):1309-22.

126. Dalbeth N, Lauterio TJ, Wolfe HR. Mechanism of action of colchicine in the treatment of gout. Clinical therapeutics. 2014;36(10):1465-79.

127. Kienle K, Lammermann T. Neutrophil swarming: an essential process of the neutrophil tissue response. Immunological reviews. 2016;273(1):76-93.

128. Lammermann T, Afonso PV, Angermann BR, et al. Neutrophil swarms require LTB4 and integrins at sites of cell death in vivo. Nature. 2013;498(7454):371-5.

129. Peters NC, Egen JG, Secundino N, et al. In vivo imaging reveals an essential role for neutrophils in leishmaniasis transmitted by sand flies. Science. 2008;321(5891):970-4 .

130. Stephen J, Scales HE, Benson RA, Erben D, Garside P, Brewer JM. Neutrophil swarming and extracellular trap formation play a significant role in Alum adjuvant activity. npj vaccines. 2017;2.

131. Gukovskaya AS, Pandol SJ, Gukovsky I. New insights into the pathways initiating and driving pancreatitis. Current opinion in gastroenterology. 2016.

132. Forsmark CE, Vege SS, Wilcox CM. Acute Pancreatitis. The New England journal of medicine. 2016;375(20):1972-81.

133. Lee SP, Nicholls JF. Nature and composition of biliary sludge. Gastroenterology. 1986;90(3):677-86.

134. Chari ST, Kloeppel G, Zhang L, Notohara K, Lerch MM, Shimosegawa T. Histopathologic and clinical subtypes of autoimmune pancreatitis: the honolulu consensus document. Pancreatology : official journal of the International Association of Pancreatology. 2010;10(6):664-72.

135. van Santvoort HC, Besselink MG, Bakker OJ, et al. A step-up approach or open necrosectomy for necrotizing pancreatitis. The New England journal of medicine. 2010;362(16): 1491-502.

136. Umapathy C, Raina A, Saligram S, et al. Natural History After Acute Necrotizing Pancreatitis: a Large US Tertiary Care Experience. Journal of gastrointestinal surgery : official journal of the Society for Surgery of the Alimentary Tract. 2016;20(11):1844-53.

137. Leppkes M, Maueroder C, Hirth S, et al. Externalized decondensed neutrophil chromatin occludes pancreatic ducts and drives pancreatitis. Nature communications. 2016;7:10973.

138. Maueroder C, Mahajan A, Paulus S, et al. Menage-a-Trois: The Ratio of Bicarbonate to $\mathrm{CO} 2$ and the $\mathrm{pH}$ Regulate the Capacity of Neutrophils to Form NETs. Frontiers in immunology. 2016;7:583. 
139. Loos M, Lauffer F, Schlitter AM, et al. Potential role of Th17 cells in the pathogenesis of type 2 autoimmune pancreatitis. Virchows Archiv : an international journal of pathology. 2015;467(6):641-8.

140. Tsen A, Alishahi Y, Rosenkranz L. Autoimmune Pancreatitis and Inflammatory Bowel Disease: An Updated Review. Journal of clinical gastroenterology. 2017;51(3):208-14.

141. Lohr JM, Schneider A, Diehl SJ, Witt H. Opie's hypothesis revisited: acute pancreatitis due to bile reflux into the pancreas. Pancreatology : official journal of the International Association of Pancreatology. 2012;12(1):39-40.

142. Banks PA, Bollen TL, Dervenis C, et al. Classification of acute pancreatitis--2012: revision of the Atlanta classification and definitions by international consensus. Gut. 2013;62(1):102-11.

143. Bilyy R, Fedorov V, Vovk V, et al. Neutrophil Extracellular Traps Form a Barrier between Necrotic and Viable Areas in Acute Abdominal Inflammation. Frontiers in immunology. 2016;7:424.

144. Merza M, Hartman H, Rahman M, et al. Neutrophil Extracellular Traps Induce Trypsin Activation, Inflammation, and Tissue Damage in Mice With Severe Acute Pancreatitis. Gastroenterology. 2015;149(7):1920-31 e8.

145. Duranton J, Belorgey D, Carrere J, Donato L, Moritz T, Bieth JG. Effect of DNase on the activity of neutrophil elastase, cathepsin $G$ and proteinase 3 in the presence of DNA. FEBS letters. 2000;473(2):154-6.

146. Long AT, Kenne E, Jung R, Fuchs TA, Renne T. Contact system revisited: an interface between inflammation, coagulation, and innate immunity. Journal of thrombosis and haemostasis : JTH. 2016;14(3):427-37.

147. Engelmann B, Massberg S. Thrombosis as an intravascular effector of innate immunity. Nature reviews Immunology. 2013;13(1):34-45.

148. Libby P, Simon DI. Inflammation and thrombosis: the clot thickens. Circulation. 2001;103(13):1718-20.

149. Esmon CT. Molecular circuits in thrombosis and inflammation. Thrombosis and haemostasis. 2013;109(3):416-20.

150. Martinod K, Wagner DD. Thrombosis: tangled up in NETs. Blood. 2014;123(18):2768-76.

151. Massberg S, Grahl L, von Bruehl ML, et al. Reciprocal coupling of coagulation and innate immunity via neutrophil serine proteases. Nature medicine. 2010;16(8):887-96.

152. Brill A, Fuchs TA, Savchenko AS, et al. Neutrophil extracellular traps promote deep vein thrombosis in mice. Journal of thrombosis and haemostasis : JTH. 2012;10(1):136-44.

153. Martinod K, Demers M, Fuchs TA, et al. Neutrophil histone modification by peptidylarginine deiminase 4 is critical for deep vein thrombosis in mice. Proceedings of the National Academy of Sciences of the United States of America. 2013;110(21):8674-9.

154. von Bruhl ML, Stark K, Steinhart A, et al. Monocytes, neutrophils, and platelets cooperate to initiate and propagate venous thrombosis in mice in vivo. The Journal of experimental medicine. 2012. 
155. Knight JS, Luo W, O'Dell AA, et al. Peptidylarginine deiminase inhibition reduces vascular damage and modulates innate immune responses in murine models of atherosclerosis. Circulation research. 2014;114(6):947-56.

156. Warnatsch A, loannou M, Wang Q, Papayannopoulos V. Inflammation. Neutrophil extracellular traps license macrophages for cytokine production in atherosclerosis. Science. 2015;349(6245):316-20.

157. Demers $M$, Krause DS, Schatzberg $D$, et al. Cancers predispose neutrophils to release extracellular DNA traps that contribute to cancer-associated thrombosis. Proceedings of the National Academy of Sciences of the United States of America. 2012;109(32):13076-81.

158. Fuchs TA, Brill A, Duerschmied D, et al. Extracellular DNA traps promote thrombosis. Proceedings of the National Academy of Sciences of the United States of America. 2010;107(36):15880-5.

159. Ward CM, Tetaz TJ, Andrews RK, Berndt MC. Binding of the von Willebrand factor A1 domain to histone. Thrombosis research. 1997;86(6):469-77.

160. Kolaczkowska E, Jenne CN, Surewaard BG, et al. Molecular mechanisms of NET formation and degradation revealed by intravital imaging in the liver vasculature. Nature communications. 2015;6:6673.

161. Kannemeier C, Shibamiya A, Nakazawa F, et al. Extracellular RNA constitutes a natural procoagulant cofactor in blood coagulation. Proceedings of the National Academy of Sciences of the United States of America. 2007;104(15):6388-93.

162. Munoz LE, Bilyy R, Biermann MH, et al. Nanoparticles size-dependently initiate selflimiting NETosis-driven inflammation. Proceedings of the National Academy of Sciences of the United States of America. 2016;113(40):E5856-E65.

163. Narasaraju T, Yang E, Samy RP, et al. Excessive neutrophils and neutrophil extracellular traps contribute to acute lung injury of influenza pneumonitis. Am J Pathol. 2011;179(1):199-210.

164. Saffarzadeh M, Juenemann C, Queisser MA, et al. Neutrophil extracellular traps directly induce epithelial and endothelial cell death: a predominant role of histones. PloS one. 2012;7(2):e32366.

165. Pieterse E, Rother N, Garsen M, et al. Neutrophil Extracellular Traps Drive Endothelial-to-Mesenchymal Transition. Arteriosclerosis, thrombosis, and vascular biology. 2017. 